\title{
Recombinant E1-deleted adenovirus vector induces apoptosis in two lung cancer cell lines
}

\author{
S. Teramoto, T. Matsuse, H. Matsui, E. Ohga, T. Ishii, Y. Ouchi
}

Recombinant E1-deleted adenovirus vector induces apoptosis in two lung cancer cell lines. S. Teramoto, T. Matsuse, H. Matsui, E. Ohga, T. Ishii, Y. Ouchi. (C)ERS Journals Ltd 1999. ABSTRACT: Although replication-defective adenoviruses (Ads) are used as vectors for delivering therapeutic genes to cancer cells, various effects of the viruses on the proliferation of lung cancer cells have been reported.

Experiments were carried out to determine whether or not E1-deleted Ad vectors (Ad5-CMV-lacZ) affected cell kinetics in two different types of lung cancer cell line in vitro.

A dose-dependent relationship was measured between the vector multiplicity of infection (MOI) and the efficiency of lac $Z$ gene transfer to lung cancer cells. The growth curves of vector-infected cells were shifted to the right compared with those of vehicle-exposed cells in a vector MOI-dependent fashion. The slowed cell proliferation resulted from both increased cell death and slower cell cycle progression of the vectorinfected cells. The morphology of vector-exposed cells revealed apoptotic features including nuclear condensation and fragmented nuclei.

These results indicate that using a higher vector MOI causes a higher gene transfer rate, but may induce apoptosis of infected cells. Although vector-induced apoptosis may be advantageous in inhibiting tumour growth, apoptosis of vector-infected cells may also reduce transgene expression in cancer cells. Minimization of the induction of apoptosis of vector-infected cells is important for the prolongation of the transduction efficiency of Ad vectors.

Eur Respir J 1999; 13: 1125-1132.
Dept of Geriatric Medicine, Tokyo University Hospital, Tokyo, Japan.

Correspondence: S. Teramoto

Dept of Geriatric Medicine

Tokyo University Hospital

7-3-1 Hongo

Bunkyo-ku

Tokyo $113-8655$

Japan

Fax: 81358006530

Keywords: Adenovirus vector apoptosis

cell cycle

gene transfer

lung cancer cells

Received: July 141998

Accepted after revision February 271999

This study was aided, in part, by grants from the Smoking Research Foundation of Japan, the Sumitomo Marine Welfare Foundation of Japan and the Ministry of Education, Science and Culture of Japan.
Replication-incompetent adenovirus (Ad)-mediated gene transfer to cancer cells is a potentially powerful tool for the in vivo delivery of therapeutic genes, such as $p 53$, to lung cancer cells $[1,2]$. Preclinical gene therapy trials are underway to test the efficacy and safety of Ad vectors in patients with lung carcinoma [3]. Since Ad vectors efficiently transduce foreign genes into a wide variety of cell types and into proliferating as well as nonproliferating cells, they are attractive candidates for the gene therapy of lung carcinoma cells, which are characterized by heterogeneity of the cell cycle $[4,5]$.

However, several limitations of controlling lung cancer growth with in vivo gene therapy using Ad vectors should be considered. Ad vectors are known to cause extensive host immune and inflammatory responses [6-8], and the immune response may be responsible for the loss of transgene expression [9]. Furthermore, Ad vector infection may affect target cell proliferation and cell death. Although ZHANG et al. [10] have demonstrated that the growth of human non-small cell lung carcinoma cells (H1299) is not affected by infection with Ad5-RSV-luciferase at a multiplicity of infection (MOI) of 100 plaqueforming units (PFU).cell ${ }^{-1}$, KATAYOSE et al. [11] have reported that an Ad vector and a replication-deficient Ad dl312 inhibit the proliferation of vascular smooth muscle cells at a MOI of $\geq 800 \mathrm{PFU}$.cell ${ }^{-1}$. It has been found that Ad vectors (Ad-CMV-lacZ and Ad-CB-CFTR) perturb proliferation of human airway epithelial cells causing apoptosis and slowing the cell cycle [12]. These observations suggest that higher MOIs of Ad vectors may be toxic to normal and/or cancer cells. The cell kinetics of Ad vector-infected lung cancer cells have, however, not been completely elucidated. Although wild-type Ad infection elicits a potent cytopathic effect in the infected cells $[13,14]$, E1 gene-deleted Ad vectors are theoretically nonreplicating, and should not induce lytic infection of host cells. It is not known, however, whether other Ad genes, present in Ad vectors, affect the proliferation of tumour cells after Ad vector-exposure.

The present study was designed to determine whether or not E1-deleted Ad vectors (Ad5-CMV-lacZ) affected cell growth in two different types of lung cancer cell line: a lung adenocarcinoma cell line and an epidermoid cell line.

\section{Methods}

\section{Adenoviral vector}

A replication-defective adenoviral vector based on the human Ad5 serotype (hAd5) was used for the study. E1 and E3 sequences were deleted from the hAd5-CMV-lacZ vector and replaced with a gene containing the cytomegalovirus (CMV) promoter and a cytoplasmic lac $Z$ gene at the site of the E1 deletion of Ad [15-18]. The Ad vector 
was propagated in HEK293 cells, purified by means of $\mathrm{CsCl}$ density gradient ultracentrifugation, and stored at $-70^{\circ} \mathrm{C}$ until used for infection of lung cancer cells. The titre of the Ad vector (in transducing units (TU) $\mathrm{mL}^{-1}$ ) was determined from the number of lac $Z$ gene-expressing HEK293 cells $\cdot \mathrm{mL}$ vector-1 by means of histochemical XGal staining [15-18]. The vector was used at titres of $1 \times 10^{11}-10 \times 10^{11}$ (TU.mL $\left.{ }^{-1}\right)$ in the experiments. The ratio of TUs to viral particle number (as measured by optical density at $260 \mathrm{~nm}$ ) was approximately 1:20-50.

\section{Cell culture}

In this study, a lung adenocarcinoma cell line (H1437) and an epidermoid cell line (A431) were used. H1437, originating from human lung cancer pleural metastases, was a generous gift from H.K. Oie (National Cancer Institute, Bethesda, MD, USA) [19]. The cells were fed on alternate days with RPMI 1640 containing $10 \%$ foetal bovine serum (FBS), penicillin and streptomycin. A431 was obtained from the American Type Culture Collection (Rockville, MD). The cells were fed on alternate days with minimum essential medium (MEM) containing 10\% FBS. The cells were maintained at $37^{\circ} \mathrm{C}$ under air plus $5 \% \mathrm{CO}_{2}$ conditions. All experiments using the cell lines were performed on a single clone.

\section{Adenovirus vector infection of lung cancer cells}

H1437 and A431 cells were plated at a density of $1 \times$ $10^{5}$ cells $\cdot w^{-1}{ }^{-1}$ in 6-well plates (Costar, Cambridge, MA, USA), allowed to attach for $12 \mathrm{~h}$ and then nonadherent cells removed by gentle washing with phosphate-buffered saline (PBS). One day after plating, the total cell number.well ${ }^{-1}$ was approximately $1 \times 10^{5}-3 \times 10^{5}(\mathrm{n}=5)$. Wells were then randomly assigned to one of six experimental groups: MOI of $1,10,10^{2}, 10^{3}$, or $10^{4}$ or vehicle control (RPMI or MEM $+0.4 \%$ FBS). The MOI was determined in HEK293 cells $[15,17]$. The Ad vector was added to the wells in $1.5 \mathrm{~mL}$ of RPMI or MEM containing $0.4 \%$ FBS, the cells exposed to it for $1 \mathrm{~h}$ at $37^{\circ} \mathrm{C}$ under air plus $5 \%$ $\mathrm{CO}_{2}$ conditions and then washed with PBS and fed with fresh RPMI or MEM containing $0.4 \%$ FBS. The control cultures were exposed to $1.5 \mathrm{~mL}$ vehicle (RPMI or MEM $+0.4 \%$ FBS).

Assessment of efficiency of gene transfer to lung cancer cells

One day after infection, the transduction efficiency was quantified as the percentage of lacZ-expressing cells via X-Gal staining [15-18]. In brief, cultured cells were washed with PBS, fixed for $8 \mathrm{~min}$ in $0.5 \%$ glutaraldehyde in PBS and then washed with PBS containing $1 \mathrm{mM} \mathrm{MgCl}$ and left for $15 \mathrm{~min}$ at $4^{\circ} \mathrm{C}$. The cells were overlaid with freshly prepared histochemical reaction mixture containing $1 \mathrm{mg} \cdot \mathrm{mL}^{-1} 5$-bromo-4-chloro-3-indolyl- $\beta$-D-galactopyranoside (X-Gal), $5 \mathrm{mM}$ potassium ferricyanide, $5 \mathrm{mM}$ potassium ferrocyanide and $1 \mathrm{mM} \mathrm{MgCl}_{2}$ in PBS for $4 \mathrm{~h}$ at $37^{\circ} \mathrm{C}$. To assess the duration of transgene expression after vector-infection, X-Gal staining was performed daily up to 7 days after Ad vector- or vehicle-exposure. In all experiments, at least three wells from each group were stained for $l a c Z$ gene expression and $>500$ cells.well ${ }^{-1}$ counted to determine the percentage of lacZ-expressing cells.

Cell growth and viability after adenovirus vector-infection

The cell proliferation rate was determined by counting the cells every other day for 7 days after Ad vectorinfection. The cell numbers in three wells from each group were calculated using a standard haemacytometer following cell detachment with $0.1 \%$ trypsin plus $1 \mathrm{mM}$ ethylenediamine-tetraacetic acid (EDTA) in PBS (trypsin-EDTA solution). Cell viability was assessed by means of their ability to exclude trypan blue. The doubling time $(t \mathrm{D})$ of the cell population was calculated according to the following formula: $t \mathrm{D}=(t-t 0) \times \log 2 /(\log N-\log N 0)$ where $N 0$ is the number of cells at day zero (to) during the log phase of the growth curve and $N$ is the number of cells at day $t$ during the log phase near the plateau of the curve.

\section{Detection of apoptosis after adenovirus vector infection of lung cancer cells}

Deoxyribonucleic acid fragmentation assay. The deoxyribonucleic acid (DNA) fragmentation assay was performed following the method described by TILLY and HSUEH [20]. DNA was extracted from H1437 cells after exposure to Ad vectors for $1 \mathrm{~h}$ at MOIs of $1,10^{2}$ or $10^{4}$ or vehicle. End-labelling $3^{\prime}$ of DNA was performed according to the method of RoychoudHURY et al. [21] using radiolabelled dideoxynucleotide $\left(\alpha-{ }^{32} \mathrm{P}\right.$-dideoxyadenosine triphosphate (ddATP) $\left(3,000 \mathrm{Ci} \cdot \mathrm{mmol}^{-1}\right)$, Amersham, Arlington Heights, IL, USA). The volume of the DNA sample in sterile water was adjusted to $29 \mu \mathrm{L}$. To these samples were added $10 \mu \mathrm{L} 5 \times$ reaction buffer $(1 \mathrm{M}$ potassium acetate, $1.25 \mathrm{mg} \cdot \mathrm{mL}^{-1}$ bovine serum albumin; $\mathrm{pH}$ 6.6), $5 \mu \mathrm{L} 25 \mathrm{mM} \mathrm{CoCl}_{2}, 5 \mu \mathrm{L} \alpha-{ }^{32} \mathrm{P}-\operatorname{ddATP}(50 \mu \mathrm{Ci})$ and $1 \mu \mathrm{L}(25 \mathrm{IU})$ terminal deoxynucleotidyl transferase (TdT) (Boehringer Mannheim, Tokyo, Japan); the mixture was incubated for $1 \mathrm{~h}$ at $37^{\circ} \mathrm{C}$. The reaction was terminated by the addition of $5 \mu \mathrm{L} 0.25 \mathrm{M}$ EDTA. Labelled DNA was separated from unincorporated radionucleotide by the addition of 0.2 volumes of $10 \mathrm{M}$ ammonium acetate, 3 volumes of $100 \%$ ethanol and $1 \mu \mathrm{L}$ $20 \mu \mathrm{g} \cdot \mu \mathrm{L}^{-1}$ glycogen for $60 \mathrm{~min}$ at $-70^{\circ} \mathrm{C}$. The nucleic acid was collected by centrifugation, washed with 0.25 $\mathrm{mL} 80 \%$ ethanol and resuspended in $20 \mu \mathrm{L} 10 \mathrm{mM}$ tris (hydroxymethyl) aminomethane (Tris)- $\mathrm{HCl}, 1$ mM EDTA (pH 7.5). DNA samples were loaded on a $2 \%$ agarose gel and separated by electrophoresis for $3.5 \mathrm{~h}$ at $50-60 \mathrm{~V}$ using $0.04 \mathrm{M}$ Tris- $\mathrm{HCl}, 0.02 \mathrm{M} \mathrm{NaOH}, 1 \mathrm{mM}$ EDTA ( $\mathrm{pH}$ 7.8) as running buffer. The gel was dried using a slab gel drier (Model SE 1160; Hoefer Scientific Instruments, San Francisco, CA, USA) for $2 \mathrm{~h}$ without heat, and exposed to Fuji radiography film (Fuji Photo Film Co., Tokyo, Japan) for $2-48 \mathrm{~h}$ at $-70^{\circ} \mathrm{C}$.

Morphological characteristics of cells after adenovirus vector-infection. Morphological characterization of cells was performed via transmission electron microscopy. One day after seeding H1437 cells $\left(10^{6}\right)$ in two $60 \mathrm{~mm}$ dishes; cells in one dish were exposed to Ad vector 
(MOI of $10^{4}, 1 \mathrm{~h}$ ) and in the other dish to vehicle $(1 \mathrm{~h})$. At $24 \mathrm{~h}$ after Ad vector exposure, the detached cells in the culture medium of the Ad vector-exposed dish were harvested by centrifugation at $200 \times g$. The adherent cells in the vehicle-exposed dish were collected using $1 \mathrm{mM}$ EDTA. The harvested cells were immediately fixed with $2 \%$ glutaraldehyde and $2 \%$ paraformaldehyde in $0.1 \mathrm{M}$ phosphate buffer ( $\mathrm{pH} 7.2)$ and then postfixed using 1\% osmium tetroxide in $0.1 \mathrm{M}$ phosphate buffer $(\mathrm{pH} 7.2)$ for $1 \mathrm{~h}$ at $4{ }^{\circ} \mathrm{C}$. After alcohol-dehydration, the cells were embedded in Epon Resin (Sigma Co., St Louis, MO, USA) according to the standard method [22, 23], and sectioned using an LKB-Huxley ultramicrotome (LKB Produkter, Bromma, Sweden) to a final thickness of 60 $90 \mu \mathrm{m}$. Sections were stained with $2 \%$ uranyl acetate and $2 \%$ lead acetate, and then examined using a Hitachi $\mathrm{H}-$ 7100 transmission electron microscope (Hitachi, Tokyo, Japan).

Quantification of apoptosis in culture dish. To determine the ratio of apoptotic cells to total cells in the culture dish, modified TdT-mediated deoxyuridine triphosphate (dUTP)-biotin nick end-labelling (TUNEL) was performed using Apoptag $®$ (Oncor Co. Gaithersburg, MD, USA) $[12,23]$. Lung cancer cells (H1437 and A431) were plated at a density of $3 \times 10^{5}$ cells.well ${ }^{-1}$ in 6 -well culture plates (Costar). One day after seeding, nine wells were exposed to each concentration of Ad vectors, at MOIs of $1,10^{2}$ and $10^{4}$, or vehicle for $1 \mathrm{hr}$. At 24,48 and $72 \mathrm{~h}$ after Ad vector-infection, the cells were harvested using trypsin-EDTA solution and stained by means of a modified TUNEL method. In brief, the cells were harvested from the culture plate using trypsin-EDTA and fixed with $2 \%$ paraformaldehyde for $15 \mathrm{~min}$ on ice. The cells were washed with PBS and collected by centrifugation $(5 \mathrm{~min}$ at $200 \times g$ ). The cells were centrifuged as before, the supernatant removed and the cells resuspended in $32 \mu \mathrm{L}$ equilibration buffer. After centrifugation for $5 \mathrm{~min}$ at $200 \times g$, the supernatant was removed and the cells incubated with $8 \mu \mathrm{L} \mathrm{TdT}$ and $19 \mu \mathrm{L}$ reaction buffer for $1 \mathrm{~h}$ at $37^{\circ} \mathrm{C}$. The reaction was terminated by the addition of $20 \mu \mathrm{L}$ stop buffer and $680 \mu \mathrm{L}$ distilled water. After centrifugation, the supernatant was removed and the pellet resuspended in $20 \mu \mathrm{L}$ anti-digoxigenin-fluorescein and $38 \mu \mathrm{L}$ blocking solution and then incubated for $30 \mathrm{~min}$ at $20^{\circ} \mathrm{C}$. Ten microlitres of $0.1 \%$ Triton X-100 in PBS was added to the cell suspension. After centrifugation, the supernatant was removed, the cells resuspended in $1 \mu \mathrm{g}$ propidium iodide (PI) (Sigma Co.) and $10 \mu \mathrm{g}$ ribonuclease (RNase) (Boehringer Mannheim Co., Tokyo, Japan) in $200 \mu \mathrm{L}$ PBS for $15 \mathrm{~min}$ and then washed with $200 \mu \mathrm{L}$ PBS. The anti-digoxigenin-fluorescein-positive (apoptotic cells) were counted using a haemacytometer and a fluorescence microscope (EPI-FL3; Nikon Microphot Tokyo, Japan). Total cell numbers were determined by counting PI-stained cells. The ratio of apoptotic to total cells in each sample ( $\geq 500$ cells counted in each sample) was calculated.

Measurement of cell cycle of lung cancer cells after adenovirus vector-infection

For cell cycle experiments, $\mathrm{H} 1437$ cells were plated at a density of $1 \times 10^{6}$ cells $\cdot$ dish $^{-1}$ in $10 \mathrm{~cm}$ culture dishes (Costar). One day after seeding, the cells were exposed to Ad vectors, at MOIs of $1,10^{2}, 10^{4}$ or vehicle for $1 \mathrm{~h}$. At 24 ,
48 and $72 \mathrm{~h}$ after Ad vector-infection, the cells were harvested using $1 \mathrm{mM}$ EDTA solution. They were then washed twice in PBS and the pellets fixed in $80 \%$ ethanol for $1 \mathrm{hr}$ at $4{ }^{\circ} \mathrm{C}$. Fixed cells were centrifuged, resuspended in PBS, recentrifuged and resuspended in a solution containing $750 \mu \mathrm{g} \cdot \mathrm{mL}^{-1} \mathrm{RNase} A$ and $50 \mu \mathrm{g} \cdot \mathrm{mL}^{-1} \mathrm{PI}$ in PBS. Samples stained with PI were analysed for DNA content using a FACScan (Becton Dickinson, San Jose, CA, USA). Cell cycle distribution was determined using CELL FIT software (San Jose, CA, USA) on a HP340 Series 9000 Workstation. Dead cells were gated out using pulse processing.

\section{Effect of inactivation of adenovirus vector on cell kinetics in lung cancer cells}

Ad vector genes were inactivated by incubation for $1 \mathrm{~h}$ at $60^{\circ} \mathrm{C}$. The effects of inactivation of Ad vector on cell proliferation were tested in lung cancer cell lines. One day after plating, cells were exposed to inactivated Ad vectors and untreated Ad vector at a MOI of $10^{4}$ or vehicle (RPMI or MEM $+0.4 \%$ FBS) for $1 \mathrm{~h}$. Cell proliferation was determined by counting the cells every other day until 7 days after Ad exposure.

\section{Statistical analysis}

Data are presented as mean \pm SD. Statistical analysis was performed using analysis of variance (ANOVA) with Fisher's protected least significant difference method or Student's t-test using Stat View 4.0 (Abacus Concepts, Inc., Berkeley, CA, USA). A p-value $<0.05$ was considered statistically significant.

\section{Results}

Kinetics of the gene transfer efficiency of the adenovirus vector in cancer cells

Although the transduction efficiency of the Ad vector was slightly better in H1437 cells than in A431 cells at MOIs of $10,10^{3}$ and $10^{4}$, there was a dose-dependent relationship between efficiency of lac $Z$ gene transfer to cancer cells and vector MOI in each cell line (fig. 1a). The changes in the percentage of lacZ-transduced cells in culture with time are depicted in figure $1 \mathrm{~b}$. In each lung cancer cell line, the transduction efficiency of the Ad vector decreased with time after Ad vector-infection (fig. 1b).

Growth curves of lung cancer cells with or without adenovirus vector-infection

The kinetics of cell proliferation in $\mathrm{H} 1437$ cells after exposure to the Ad vector or vehicle was similar to that in A431 cells. The growth curves of Ad vector-infected cells were shifted to the right in a MOI-dependent manner (fig. 2 ). While the accelerated phase of the growth curve was initiated one day after vehicle-exposure, log phase growth 

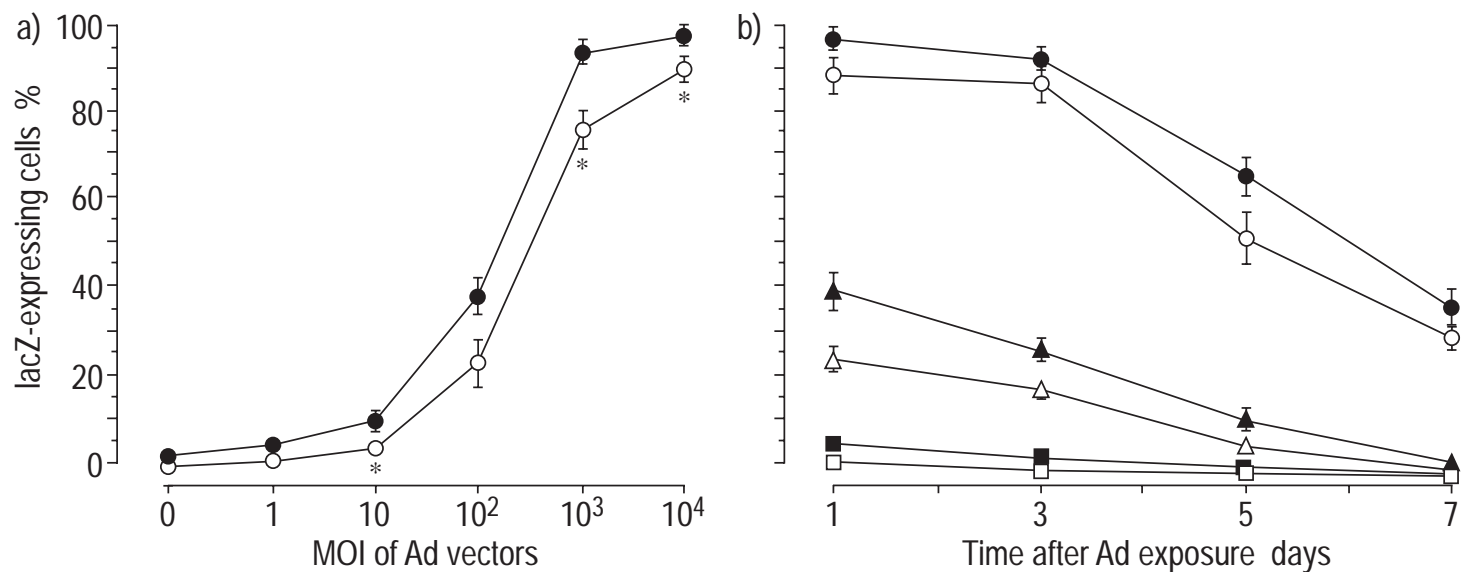

Fig. 1. - The efficiency of: a) hAd5-CMV-lacZ-mediated gene (lacZ) transfer in H1437 (๑) and A431 cells ( $\bigcirc) 1$ day after infection (*: p<0.05 versus H1437); and b) transduction of Adenovirus (Ad) vector with time after Ad vector infection of H1437 ( $\mathbf{\square}$ : multiplicity of infection (MOI) $1 ; \mathbf{\Delta}$ : MOI 10²; : MOI $10^{4}$ ) and A431 cells ( $\square$ : MOI $1 ; \triangle$ : MOI $10^{2} ; \bigcirc:$ MOI $10^{4}$ ).

started 3 days after Ad vector-infection in both cell lines. The delayed onset of log phase growth was caused by the longer $t$ D of Ad-infected cells compared to that of vehicleexposed cells (table 1). Further, the viability of the cells, as determined by trypan blue exclusion, was lower in vector-exposed cells than in vehicle-exposed cells (fig. 3). The lower viability of the Ad vector-infected cells compared with vehicle-exposed cells lasted $\geq 48 \mathrm{~h}$ after Ad vector-infection.
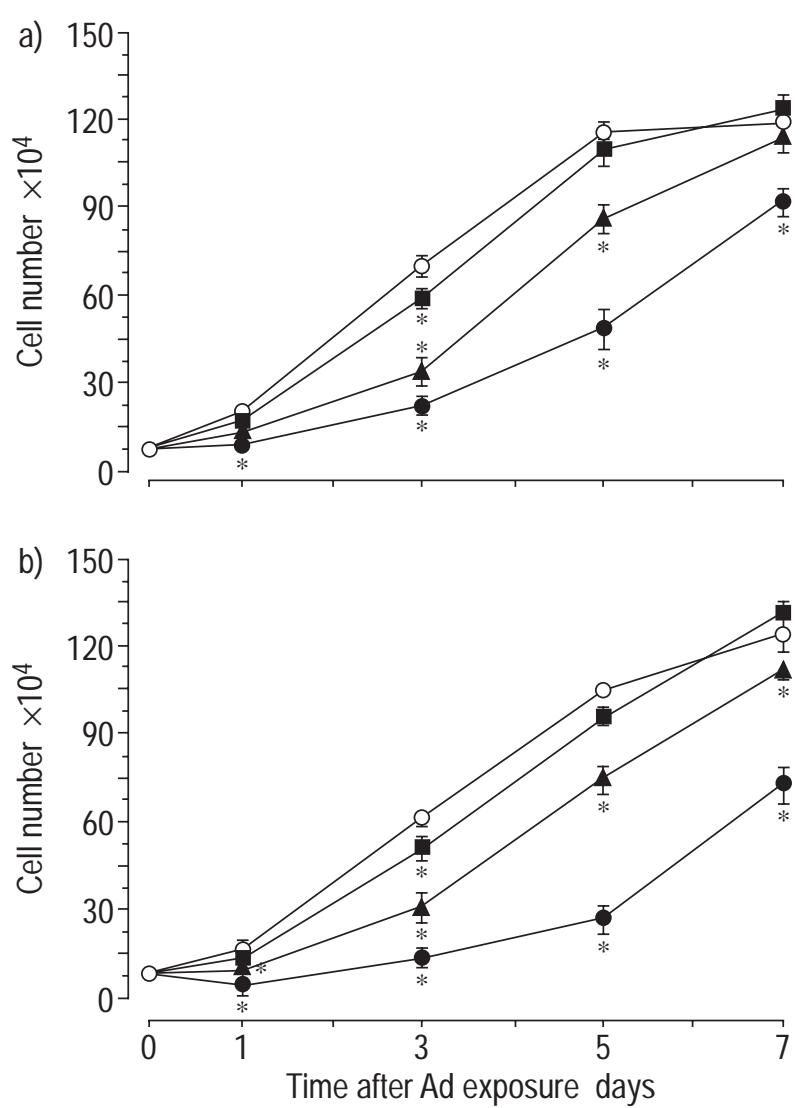

Fig. 2. - Kinetics of cell proliferation after exposure to hAd5-CMVlacZ (田: multiplicity of infection) MOI $1 ; \mathbf{\Delta}$ : MOI $10^{2} ; \bullet:$ MOI $10^{4}$ ) or vehicle $(O)$ in: a) H1437; and b) A431 cells. Values represent mean \pm SD $(\mathrm{n}=3)$. Ad: adenovirus. *: $\mathrm{p}<0.05$ versus vehicle.
Detection of apoptosis in adenovirus vector-infected cells

DNA integrity analysis utilizing agarose gel electrophoresis of $\mathrm{H} 1437$ cells with or without Ad vector-exposure is shown in figure 4. DNA fragmentation was not obvious in the DNA extracted from vehicle-exposed cells. On the other hand, DNA fragmentation was clearly present in DNA extracted from cells exposed to Ad vector at a higher MOI. Transmission electron micrographs of vehicleexposed H1437 cells and Ad vector-exposed H1437 cells are shown in figure 5. Compared with vehicle-exposed cells, Ad vector-infected cells (MOI of $10^{4}$ ) revealed the features of apoptosis, such as cell shrinkage, nuclear condensation and fragmentation, and apoptotic body formation. Morphological features of apoptosis were found in cells infected with Ad vector at MOIs of $10^{4}$ and $10^{2}$. However, the percentage of apoptotic cells was lower in cells infected with Ad vector at MOIs of 1 and $10^{2}$ than in those infected at a MOI of $10^{4}$. The percentage of apoptotic cells was quantified by means of DNA strand breaks detected using TUNEL (fig. 6). The ratio of apoptotic (TUNEL-positive) cells to total cells increased with increasing vector MOI. However, the number of apoptotic cells after Ad vector-infection decreased with time in culture.

Table 1. - Doubling time (tD) of lung cancer cell lines with and without adenovirus (Ad) vector-exposure

\begin{tabular}{lcc}
\hline & \multicolumn{2}{c}{$t$ D days } \\
\cline { 2 - 3 } Vector & H1437 & A431 \\
\hline Vehicle & $1.55 \pm 0.06$ & $1.55 \pm 0.07$ \\
Ad, MOI 1 & $1.53 \pm 0.07$ & $1.62 \pm 0.12$ \\
Ad, MOI 10 & $1.70 \pm 0.13$ & $1.75 \pm 0.14$ \\
Ad, MOI 10 & $1.81 \pm 0.11$ & $1.88 \pm 0.16$ \\
UV-inactivated Ad, MOI 10 & $1.56 \pm 0.06$ & $1.56 \pm 0.10$ \\
\hline
\end{tabular}

Values are presented as mean \pm SD. $t \mathrm{D}$ was calculated according to the formula given in Methods. MOI: multiplicity of infection; UV-inactivated Ad: ultraviolet plus psolaren-inactivated Ad vectors. 


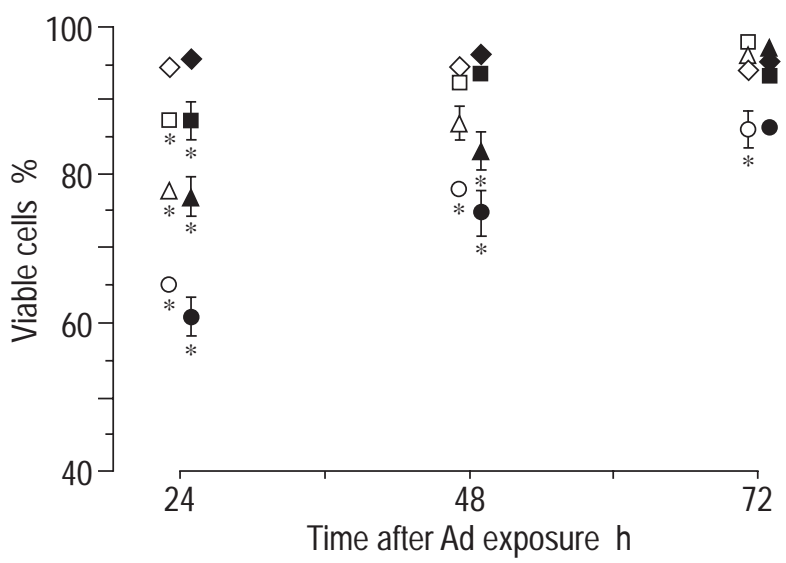

Fig. 3. - Viability of cells as determined by trypan blue exclusion as a function of time after vector or vehicle (H1437: $\diamond$; A431: $\diamond)$-exposure of H1437 ( $\boldsymbol{\square}$ : multiplicity of infectoin (MOI) $1 ; \boldsymbol{\Delta}$ : MOI $10^{2} ; \boldsymbol{\bullet}:$ MOI $10^{4}$ ) and A431 cells ( $\square$ : MOI 1; $\triangle$ : MOI $10^{2}$; $\bigcirc$ : MOI $10^{4}$ ). Values are presented as mean \pm SD $(n=3)$. Ad: adenovirus. *: $\mathrm{p}<0.05$ versus vehicle.

\section{Effect of adenovirus vector-infection on cell cycle in lung cancer cells}

The percentage of cells in the DNA synthetic (S) phase after Ad vector-exposure was lower than that after vehicle-exposure. There was a decrease in the number of cells in the S phase 24-48 h after Ad vector-exposure, accompanied by an increase in the percentage of cells in the quiescent $\left(\mathrm{G}_{2}\right)$ /mitosis $(\mathrm{M})$ phase (fig. 7). There was no difference in the percentage of cells in the interphase $\left(\mathrm{G}_{1}\right)$ phase between vector- and vehicle-exposed cells. In cells infected with Ad vector at a MOI of $10^{2}$, a reduction in the number of cells in the $\mathrm{S}$ phase $24-48 \mathrm{~h}$ after Ad vector-exposure, accompanied by an increase in the percentage of cells in the $\mathrm{G}_{2} / \mathrm{M}$ phase, was also observed. However, this alteration of the cell cycle was not observed in the cells infected with Ad vector at a MOI of 1.

Effect of heat-inactivation of genes of Ad-CMV-lacZ on the growth kinetics of lung cancer cells

The effect of heat-inactivation of genes of hAd5-CMVlac $Z$ on the proliferation of cancer cells is shown in figure 8. There was no difference in growth curves between heat-inactivated Ad vector $\left(\mathrm{MOI}=10^{4}\right)$-exposed cells and vehicle-exposed cells. The doubling times of cells after exposure to Ad vector or heat-inactivated Ad vector are presented in table 1 . Inactivation of vector genes almost completely abrogated the Ad vector effects on cell kinetics in lung cancer cells. In addition, there was no difference in growth curves between heat-inactivated Ad vector $\left(\mathrm{MOI}=10^{2}\right)$-exposed cells and vehicle-exposed cells, or between heat-inactivated Ad vector (MOI 1)exposed cells and vehicle-exposed cells

\section{Discussion}

The present study demonstrated that E1-deleted Ad vector-infection inhibited proliferation of cultured lung carcinoma cells. The retarded growth after Ad vectorinfection was characterized by both the delayed onset of log phase growth and slower proliferation during the $\begin{array}{llll}1 & 2 & 3 & 4\end{array}$

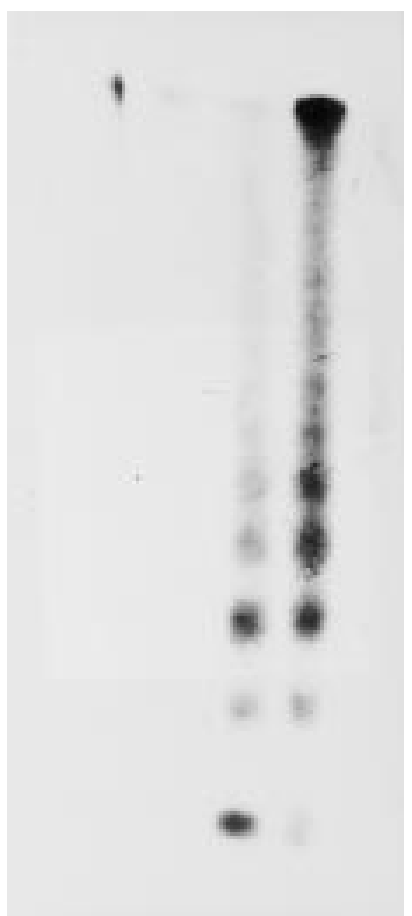

Fig. 4. - Deoxyribonucleic acid (DNA) integrity analysis ("DNA ladder") utilizing agarose gel electrophoretic separation of $\alpha-{ }^{32} \mathrm{P}$-dideoxyadenosine triphosphate $3^{\prime}$ end-labelled DNA samples from H1437 cells exposed to vector (hAd5-CMV-lacZ, lane 2: multiplicity of infection (MOI) 1; lane 3: MOI $10^{2}$; lane 4: MOI $10^{4}$ ) or vehicle (lane 1). Each sample consisted of cells harvested from dishes $24 \mathrm{~h}$ after exposure to vector or vehicle. The material in each lane was extracted from the same amount of DNA (200 ng)

accelerated growth phase, as indicated by the longer $t \mathrm{D}$. It can be assumed that the increased apoptotic death of vector-infected cells was associated with the delayed onset of log phase growth. In fact, Ad vector infection with a high MOI reduced the viability of lung cancer cell lines. The morphology of the cells after Ad vector-exposure revealed apoptotic features including cell shrinkage and nuclear condensation and fragmentation [12, 24]. Internucleosomal DNA fragmentation was increased in Ad vector-infected cells in a vector titre-dependent manner. This finding was confirmed by the increased formation of DNA strand breaks in Ad vector-exposed cells, as determined by the TUNEL assay. However, whereas these findings were clear-cut in cells infected with a high MOI, they were less obvious in those with a low MOI, suggesting that a high MOI of recombinant-defective Ad vector can induce apoptosis in lung cancer cells lines.

Many Ad early genes, including E1a and E3, are known to induce apoptosis and/or inhibit cytolysis in infected cells [25-27]; these genes have been deleted from Ad vectors utilized for cancer gene therapy. It has not yet been determined whether or not other Ad genes present in Ad vectors can induce or inhibit the apoptotic cell death of lung cancer cells. Further since lung cancer cells can be immortalized by oncogenes involved in induction and/or inhibition of apoptosis, the mechanism of Ad vector-induced apoptosis in lung cancer cells may not be straightforward. Several lines of evidence suggest that Ad gene products increase p53 levels and induce p53-dependent 

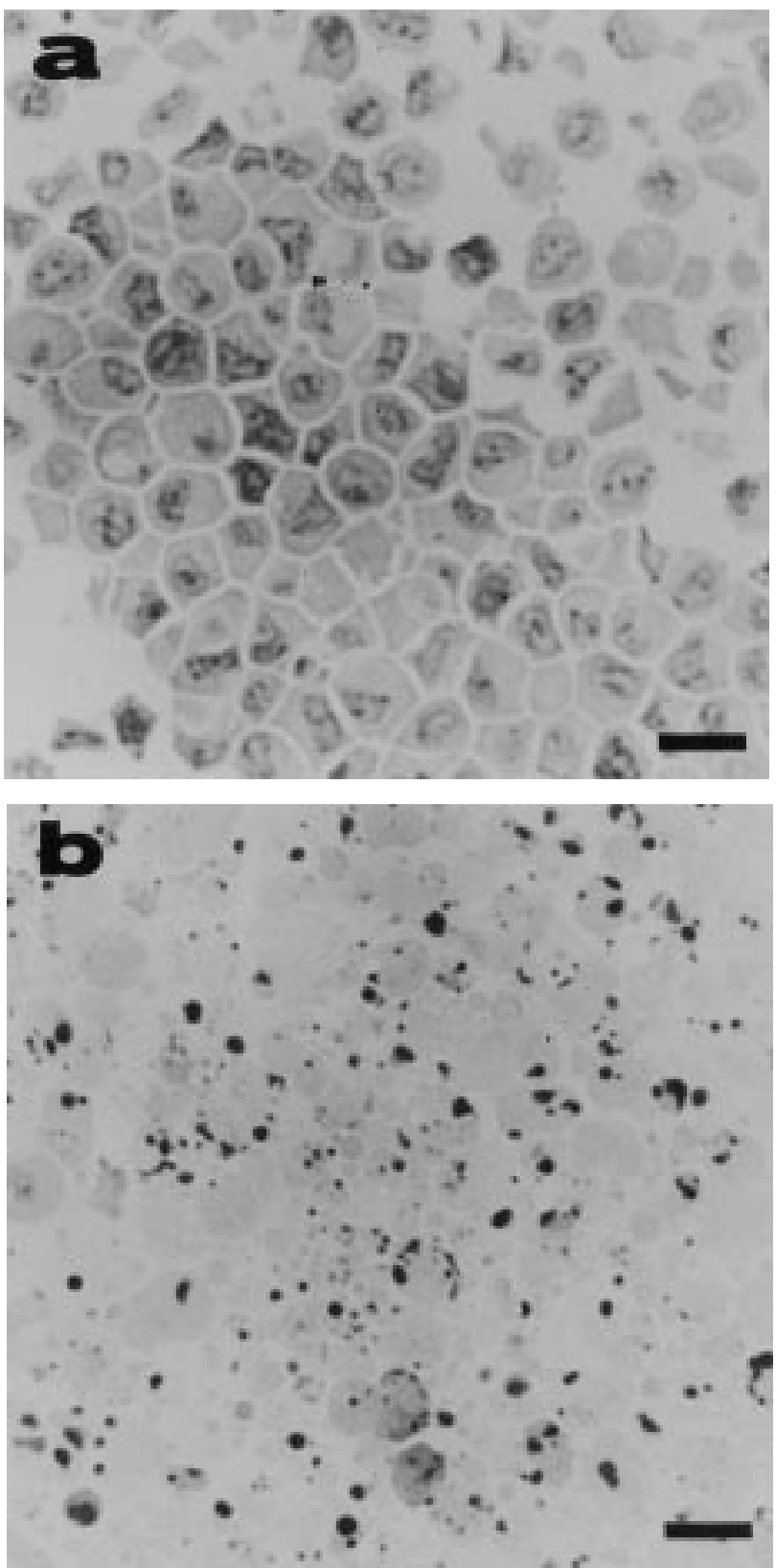

Fig. 5. - Transmission electron micrographs of: a) adherent vehicleexposed H1437 cells harvested from the culture dish using ethylenediamine tetraacetic acid solution; and b) detached H1437 cells exposed to adenovirus vector (hAd5-CMV-lacZ) at a multiplicity of infection (MOI) of $10^{4}$. Internal scale bar $=20 \mu \mathrm{m}$.

apoptosis [26, 27]. However, KatAYose et al. [28] have reported that E1a/E1b region-deleted Ad vectors do not upregulate $p 53$ expression in certain cells. SuBRAMANIAN et al. [29] have found that E1b-partially deleted $19 \mathrm{k}$ mutant adenoviruses induce apoptosis in primary mouse kidney cells prepared from $p 53(+/+)$ as well as $p 53(-/-)$ mice. These observations suggest that $p 53$ expression may not play a major role in Ad vector-induced apoptosis in lung cancer cells. In the present study, the growthinhibition caused by Ad vector-infection was investigated in two cancer cell lines and found to be similar, indicating that Ad genes rather than oncogenes present in the cancer cells are involved in the mechanism of apoptosis. How-

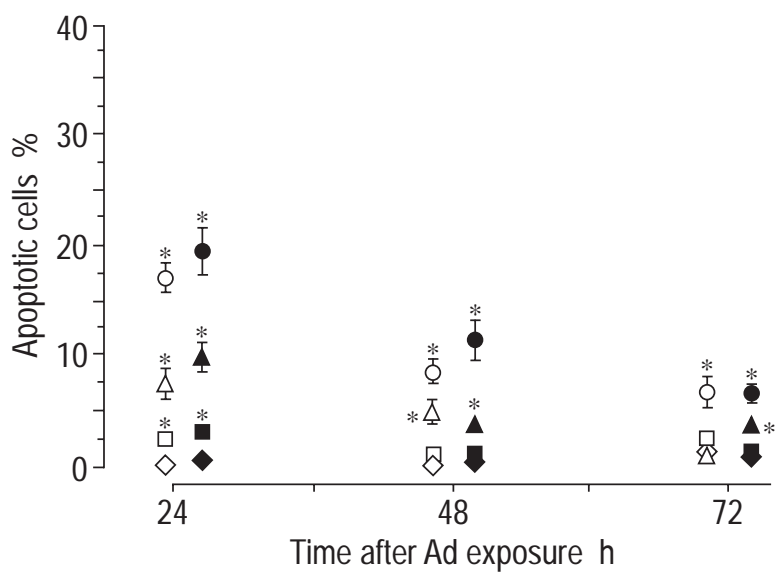

Fig. 6. - Effect of adenovirus (Ad) vector (hAd5-CMV-lacZ)-infection on induction of apoptosis in H1437 ( $\mathbf{\square}$ : multiplicity of infection (MOI) 1; $\boldsymbol{\Delta}$ : MOI $10^{2}$; 0 : MOI $10^{4}$ ) and A431 cells ( $\square$ : MOI $1 ; \triangle$ : MOI $10^{2}$; $\mathrm{O}$ : MOI $10^{4}$ ). Apoptosis was measured using terminal deoxynucleotidyl transferase-mediated deoxyuridine triphosphate-biotin nick end-labelling. Values are presented as mean $\pm S D(n=3)$. *: $\mathrm{p}<0.05$ versus vehicle.

ever, the greater amount of vector protein present at a higher MOI seems to be harmful to cells in culture. Thus, whether vector-induced apoptosis was due to vector gene expression or vector proteins was examined. The results demonstrated that heat-inactivation of vector genes almost entirely abolished the effect, suggesting that apoptosis reflects vector gene expression rather than the toxicity of vector proteins. BRough et al. [30] have demonstrated that E1- and E4-deleted Ad vector achieves persistent transgene expression in the liver and lungs of mice [30]. In addition, it has recently been reported that adenovirus type $5 \mathrm{E} 4$ open reading frame 4 induces apoptosis in transformed cells in vitro [31, 32]. Taken together, these results indicate that Ad E4 genes present in the current E1- and E3-deleted Ad vectors may be responsible for the vector-induced apoptosis of lung cancer cells.

Cell cycle distribution was examined after Ad vectorinfection of cancer cells by means of FACScan analysis after staining with PI. Although the percentage of cells in

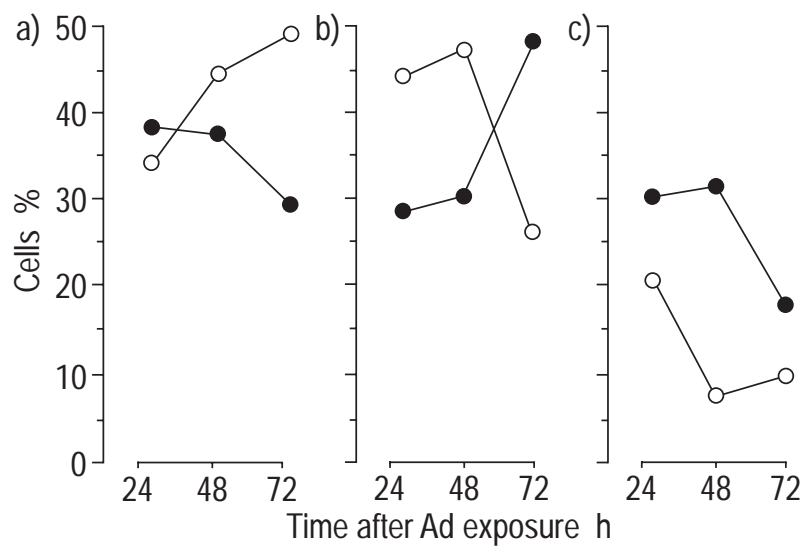

Fig. 7. - Effect of adenovirus (Ad) vector (hAd5-CMV-lacZ)-infection on the cell cycle in lung cancer cells. The percentages of cells in: a) the interphase $\left(\mathrm{G}_{1}\right)$; b) the deoxyribonucleic acid synthetic $(\mathrm{S})$; and $\mathrm{c}$ ) the quiescent $\left(\mathrm{G}_{2}\right)$ /mitosis $(\mathrm{M})$ phases of the cell cycle are presented as a function of time after Ad vector-infection. $\bigcirc$ : vehicle-exposed cells; Ad vector (MOI 104)-exposed cells. 

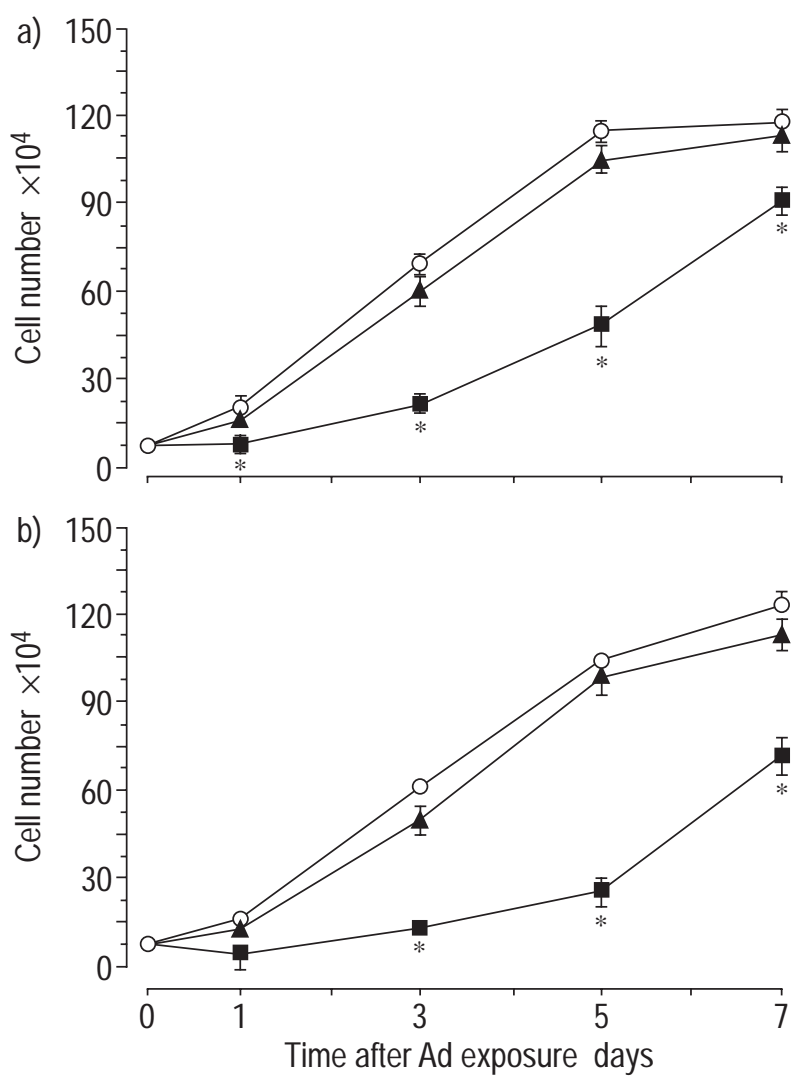

Fig. 8. - Effect of heat-inactivation of adenovirus (Ad) vector $(O$ : vehicle; $\boldsymbol{\Delta}$ : ultraviolet-inactivated Ad, multiplicity of infection (MOI) $10^{4}$; $\mathbf{\square}$ : Ad, MOI $10^{4}$ ) on proliferation of a) H1437; and b) A431 cells. Values are presented as mean $\pm \mathrm{SD}(\mathrm{n}=3)$. *: $\mathrm{p}<0.05$ versus vehicle.

$\mathrm{G}_{1}$ was not different between vector- and vehicle-exposed cells, a decrease in the number of cells in the $S$ phase accompanied by an increase in the percentage of cells in the $\mathrm{G}_{2} / \mathrm{M}$ phase was found in Ad vector-exposed cells. Thus, the longer $t \mathrm{D}$ of vector-exposed cells may be explained by the lower percentage of cells recruited into the $S$ phase after Ad vector-exposure. Although apoptosis is closely associated with $\mathrm{G}_{1}$ arrest in several cell types [33, 34], the present results indicate that apoptosis caused by Ad vector is not always related to $G_{1}$ arrest. Since there are two points, the transitions between $\mathrm{G}_{1} / \mathrm{S}$ and $\mathrm{G}_{2} / \mathrm{M}$, at which DNA damage is monitored, the accumulation of cells in the $\mathrm{G}_{2} / \mathrm{M}$ transition phase may be associated with Ad vector-induced apoptosis in cancer cells.

In the current study, the efficiency of Ad vector-mediated gene transfer to cancer cells confirmed that previous reports $[1-3,10]$. Replication-incompetent Ads are efficient vectors, having a high efficiency of gene transfer, compared with other vector systems, in culture. However, the transduction efficiency of the Ad vector was slightly different in the two cancer cell lines investigated. The present study thus, suggests that adenocarcinoma may be better transduced by Ad vectors than is squamous cell carcinoma. Although replication-defective Ad vectors are known to infect various types of cells, the efficiency of Ad-mediated gene transfer is not the same in different types of cells [15-17, 35]. Further studies are needed to elucidate the relationship between lung cancer cell type and the gene transfer efficiency of Ad vectors.
In summary, adenovirus vector-mediated gene transfer to lung cancer cells was highly efficient in a multiplicity of infection-dependent fashion. Adenovirus vectors at higher multiplicities induced apoptotic cell death in adenovirus vector-infected cancer cells and subsequently reduced the transduction efficiency of adenovirus vectors with time. Since a higher multiplicity of infection of adenovirus vectors may be necessary to transduce foreign gene into target cells in vivo, adenovirus vector-induced apoptosis may reduce transgene expression in lung cancers. These effects of adenovirus vectors on cell kinetics are disadvantageous to the efficacy of gene therapy of lung carcinoma. Elimination of these effects of adenovirus vectors on lung cancer cells may be important in improving the efficacy of adenovirus-mediated gene therapy.

\section{References}

1. Hwang HC, Smythe WR, Elshami AA, et al. Gene therapy using adenovirus carrying the herpes simplexthymidine kinase gene to treat in vivo models of human malignant mesothelioma and lung cancer. Am J Respir Cell Mol Biol 1995; 13: 7-16.

2. Heike Y, Takahashi M, Kagnegae Y, Saito Y, Saito I, Saijo N. Interleukin-2 gene transduction into freshly isolated lung adenocarcinoma cells with adenoviral vectors. Hum Gene Ther 1997; 8: 1-14.

3. Gahay-Segard H, Molinier-Frebkel Y, Le Boulaire C, et al. Phase I trial of recombinant adenovirus gene transfer in lung cancer. Longitudinal study of the immune responses to transgene and viral products. $J$ Clin Invest 1997; 100: 2218-2226.

4. Curiel DT, Pilewski JM, Albelda SM. Gene therapy approach for inherited and acquired lung diseases. $\mathrm{Am} J$ Respir Cell Mol Biol 1996; 14: 1-18.

5. Albelda SM. Gene therapy for lung cancer and mesothelioma. Chest 1997; 111(Suppl. 6): 144S-149S.

6. Yang Y, Nunes FA, Berencsi K, Gonczol E, Engelhardt JF, Wilson JM. Cellular immunity to viral antigens limits E1-deleted adenoviruses for gene therapy. Proc Natl Acad Sci USA 1994; 91: 4407-4411.

7. Simon RH, Engelhardt JF, Yang Y, et al. Adenovirusmediated transfer of the CFTR gene to lung of nonhuman primates: toxicity study. Hum Gene Ther 1993; 4: 821836.

8. Yei S, Mittereder N, Wert S, Whitsett JA, Wilmott RW, Trapnell BC. In vivo evaluation of the safety of adenovirus-mediated transfer of the human cystic fibrosis transmembrane conductance regulator cDNA to the lung. Hum Gene Ther 1994; 5: 731-744.

9. Tripathy SK, Black HB, Goldwasser E, Leiden JM. Immune responses to transgene-encoded proteins limit the stability of gene expression after injection of replication-defective adenovirus vectors. Nat Med 1996; 2: 545-550.

10. Zhang W-W, Alemany R, Wang J, Koch PE, Ordonez N, Roth JA. Safety evaluation of Ad5CMV-P53 in vitro and in vivo. Hum Gene Ther 1995; 6: 155-164.

11. Katayose D, Wersto R, Cowan K, Seth P. Consequences of $\mathrm{p} 53$ gene expression by adenovirus vector on cell cycle arrest and apoptosis in human aortic vascular smooth muscle cells. Biochem Biophys Res Commun 1995; 215 : 446-451.

12. Teramoto S, Johnson LG, Huang W, Leigh MW, Boucher RC. Effect of adenoviral vector infection on cell 
proliferation in cultured primary human airway epithelial cells. Hum Gene Ther 1995; 6: 1045-1053.

13. Boyer GS, Denny FW Jr, Ginsberg HS. Sequential cellular changes produced by types 5 and 7 adenoviruses in HeLa cells and in human amniotic cells. $J$ Exp Med 1959; 110: 827-844.

14. Zhang Y, Schneider RJ. Adenovirus inhibition of cell translation facilitates release of virus particles and enhances degradation of the cytokeratin network. $J$ Virol 1994; 68: 2544-2555.

15. Teramoto S, Matsuse T, Ohga E, Nagase T, Fukuchi Y, Ouchi Y. Kinetics of adenovirus-mediated gene transfer to human lung fibroblasts. Life Sci 1997; 61: 891-897.

16. Teramoto S, Ito H, Ouchi Y. Variables affecting the transduction efficiency of adenovirus vectors in bovine aortic endothelial cells. Thromb Res 1999; 93: 35-42.

17. Teramoto S, Bartlett JS, McCarty D, Xiao X, Sumulski RJ, Boucher RC. Factors influencing adeno-associated virus-mediated gene transfer to human cystic fibrosis airway epithelial cells: a comparison with adenovirus vector. $J$ Virol 1998; 72: 8904-8912.

18. Teramoto S, Matsuse T, Oka T, Ito H, Fukuchi Y, Ouchi Y. Investigation of effects of anesthesia and age on aspiration in mice using lac $Z$ gene transfer by recombinant E1-deleted adenovirus vectors. Am J Respir Crit Care Med 1998; 158: 1914-1919.

19. Hoganson DK, Batra RK, Oleson JC, Boucher RC. Comparison of the effects of three different toxin genes and their levels of expression on cell growth and bystander effect on lung adenocarcinoma. Cancer Res 1996; 56 : 1315-1323.

20. Tilly JL, Hsueh AJW. Microscale autoradiographic method for the qualitative and quantitative analysis of apoptotic DNA fragmentation. J Cell Physiol 1993; 154: 519-526.

21. Roychoudhury R, Jay E, Wu R. Terminal labeling and addition of homopolymer tracts of duplex DNA fragments by terminal deoxynucleotidyl transferase. Nucleic Acids Res 1976; 3: 863-877.

22. Bertram JF, Soosaipillai MC, Ricardo SD, Ryan GB. Total numbers of glomeruli and individual glomerular cell types in the normal rat kidney. Cell Tissue Res 1992; 270: $37-45$.

23. Teramoto S, Tomita T, Ohga E, Matsui H, Matsuse T, Ouchi Y. Hydrogen peroxide-induced apoptosis and ne- crosis in human lung fibroblasts: protective roles of glutathione. Jpn J Pharmacol 1999; 79: 33-40.

24. Kerr JF, Wyllie AH, Currie AR. Apoptosis: a basic biological phenomenon with wide-ranging implications in tissue kinetics. Br J Cancer 1972; 26: 239-257.

25. White E, Sabbatini P, Debbas M, Wold WSM, Kusher DI, Gooding L. The 19-kilodalton adenovirus E1B transforming protein inhibits programmed cell death and prevents cytolysis by tumor necrosis factor. $\mathrm{Mol}$ Cell Biol 1992; 12: 2570-2580.

26. Lowe SW, Ruley EH. Stabilization of the p53 tumor suppressor is induced by adenovirus $5 \mathrm{E} 1 \mathrm{~A}$ and accompanies apoptosis. Genes Dev 1993; 7: 535-545.

27. Teodoro JG, Branton PK. Regulation of apoptosis by viral gene products. J Virol 1997; 71: 1739-1746.

28. Katayose D, Wersto R, Cowan K, Seth P. Effects of reexpressing WAF/Cip1 on cell growth, cell cycle, and apoptosis. Cell Growth Differ 1995; 6: 1207-1212.

29. Subramanian T, Tarodi B, Chinnadurai G. p53-independent apoptoic and necrotic cell deaths induced by adenovirus infection: suppression by $\mathrm{E} 1 \mathrm{~B} 19 \mathrm{~K}$ and $\mathrm{Bc} 1-2$ proteins. Cell Growth Differ 1995; 6: 131-137.

30. Brough DE, Hsu C, Kulesa VA, Lee GA, et al. Activation of transgene expression by early region 4 is responsible for a high level of persistent transgene expression from adenovirus vector in vivo. J Virol 1997; 71: 9206-9213.

31. Lavoie JN, Nguyen M, Marcellus RC, Branton PE, Shore GC. E4orf4, a novel adenovirus death factor that induces p53-independent apoptosis by a pathway that is not inhibited by zVAD-fmk. J Cell Biol 1998; 140: 637-645.

32. Shtrichman R, Kleinberger T. Adenovirus type 5 E4 open reading fame 4 protein induces apoptosis in transformed cells. J Virol 1998; 72: 2975-2982.

33. Strasser A, Harris AW, Jacks T, Cory S. DNA damaging can induce apoptosis in proliferating lymphoid cells via p53-independent mechanisms inhibitable by Bc1-2. Cell 1994; 79: 329-339.

34. Murakami T, Li X, Gong J, Bhatia U, Traganos F, Darzyniewicz Z. Induction of apoptosis by 5 -azacytidine: drug concentration-dependent differences in cell cycle specificity. Cancer Res 1995; 55: 3093-3098.

35. Grubb B, Pickles RJ, Ye H, et al. Inefficiency of in vivo gene transfer by adenovirus vector to cystic fibrosis airway epithelia of mice and humans. Nature 1994; 371 : 802-826. 